\title{
On the Use of Adaptive Resemblance Terms in Chemical Ecology
}

\author{
Christoph von Beeren, Sebastian Pohl, and Volker Witte \\ Department of Biology II, Ludwig Maximilians University Munich, Großhaderner Straße 2, 82152 Planegg-Martinsried, Germany
}

Correspondence should be addressed to Volker Witte, witte@biologie.uni-muenchen.de

Received 12 September 2011; Revised 7 November 2011; Accepted 8 November 2011

Academic Editor: Alain Lenoir

Copyright () 2012 Christoph von Beeren et al. This is an open access article distributed under the Creative Commons Attribution License, which permits unrestricted use, distribution, and reproduction in any medium, provided the original work is properly cited.

\begin{abstract}
Many organisms (mimics) show adaptive resemblance to an element of their environment (model) in order to dupe another organism (operator) for their own benefit. We noted that the terms for adaptive resemblance are used inconsistently within chemical ecology and with respect to the usage in general biology. Here we first describe how resemblance terms are used in general biology and then comparatively examine the use in chemical ecology. As a result we suggest the following consistent terminology: "chemical crypsis" occurs when the operator does not detect the mimic as a discrete entity (background matching). "Chemical masquerade" occurs when the operator detects the mimic but misidentifies it as an uninteresting entity, as opposed to "chemical mimicry" in which an organism is detected as an interesting entity by the operator. The additional terms "acquired" and "innate" may be used to specify the origins of mimetic cues.
\end{abstract}

\section{Introduction}

Social insects, especially ants and termites, dominate many terrestrial habitats in terms of abundance, biomass, and energy turnover $[1,2]$. They accumulate considerable amounts of resources that can be of potential use for other organisms, in the form of living biomass, infrastructures (e.g., nest sites), or stored products [3]. The ecological success of social insects comes with the cost that predators and parasites may exploit their societies [4-6]. Since Wasmann's [7] extensive study on organisms that developed close relationships with ants, a multitude of so-called myrmecophiles has been found to exploit ant colonies and their social resources in a variety of ways $[5,8]$. Parasitic relationships may escalate in an evolutionary arms race where the hosts adapt towards protecting themselves from exploitation, while parasites adapt towards avoiding expulsion from the host [9].

In this context it is crucial that members of a society can be recognized reliably and distinguished from aliens, which can thus be aggressively expelled [10]. An efficient social recognition system is essential for a colony to function as a closed unit. The better such recognition works, the more effectively social exploitation can be prevented. Complex profiles of cuticular hydrocarbons (CHCs) are known to carry information necessary for recognition of colony members in ants, bees, and wasps [10].

Macroparasites of ants have evolved a variety of strategies to cope with their hosts' elaborate recognition system [5]. Potential strategies for avoiding or resisting the hosts' defense behavior include the use of morphological, acoustical, and behavioral adaptations or the use of chemical repellents or attractants [1, 5, 11-13]. Particularly widespread and important are chemical strategies for avoiding recognition, either by not expressing relevant recognition cues or by matching host recognition cues $[11,14,15]$. For simplicity, we use the term "cue" referring to any chemical information that is potentially perceivable, irrespective of whether the information transfer is "intentional" or "unintentional" sensu Steiger et al. [16].

Chemical resemblances work analogously to other biological resemblances, such as acoustic or visual mimicry [17]. Unfortunately, different definitions exist in chemical ecology (see below), and thus different authors may describe different forms of chemical resemblances with identical terms or the same type of resemblance with different terms.

The aim of this paper is threefold. First, we identify how definitions of resemblances are generally used in biology. Second, we analyze the terminology that is used in chemical 
TABLE 1: Summarized table of adaptive resemblance terms in general biology as used in important reviews. Systems can either be considered according to what a mimic pretends to be or according to what an operator perceives. We adopted the latter view.

\begin{tabular}{|c|c|c|c|}
\hline $\begin{array}{l}\text { not detected as a discrete entity } \\
\text { (causing no reaction) }\end{array}$ & $\begin{array}{l}\text { By an operator, the mimic is... } \\
\text { detected as an uninteresting } \\
\text { entity (causing no reaction) }\end{array}$ & $\begin{array}{l}\text { detected as an interesting entity } \\
\text { (causing a reaction beneficial } \\
\text { to the mimic) }\end{array}$ & Reference(s) \\
\hline Crypsis & Masquerade & Mimicry & Endler 1981 [21], 1988 [22] \\
\hline Eucrypsis & Mimesis & Homotypy & Pasteur $1982^{\mathrm{a}}[23]$ \\
\hline Eucrypsis & Plant-part mimicry & Mimicry & Robinson $1981[24]$ \\
\hline Crypsis & Masquerade & Mimicry & Ruxton et al. 2004 [25], Ruxton 2009 [17] \\
\hline Cryptic resemblance & Cryptic resemblance & Sematic resemblance & Starrett $1993[18]$ \\
\hline Crypsis & Masquerade & - & Stevens and Merilaita 2009 $[26]$ \\
\hline Crypsis & Crypsis & Mimicryc & Vane-Wright 1976 [27], 1980 [20] \\
\hline Camouflage or mimesis & Camouflage or mimesis & Mimicry & Wickler $1968[19]$ \\
\hline
\end{tabular}

-: not considered.

aPasteur [23] uses the term "camouflage" as generic term for both eucrypsis and mimesis.

b The term "camouflage" is used by Stevens and Merilaita [26] to describe all forms of concealment, including crypsis and masquerade.

'For the imitation of inanimate objects, Vane-Wright [27] uses the expressions "decoys" or "deflective marks".

ecology. Finally, we attempt a synthesis and suggest a terminology that agrees best with the general biological definitions and with the chemical strategies observed in nature.

\section{General Definitions of Biological Resemblances}

Since the resemblance of organisms to elements of their environment (e.g., other organisms or background) is often not coincidental, but rather evolved for the benefit of the mimic, the term adaptive resemblance was coined [18]. In adaptive resemblance one organism (the mimic) modifies its appearance, pretending to be something different (the model), in order to dupe another organism (the operator) $[19,20]$. Many different terms have been used to describe adaptive resemblance, including mimicry, camouflage, crypsis, masquerade, and mimesis. These terms have been debated intensively and defined repeatedly according to different criteria (see Table 1).

For the purpose of this paper, we adopted an operator's view to narrow down the existing definitions of adaptive resemblance into a unified system. This means that we distinguish the cues of a mimic with respect to whether and how they are perceived by the operator. The resulting categories are only valid within a given perceptive channel between mimic and operator, and they can differ in other channels or if other organisms are considered. The first column of Table 1 defines resemblances in which a mimic is not perceived as a discrete entity by the operator and consequently causes no reaction in the operator. In such cases the mimic frequently blends with the background. We adopt the term "crypsis" for this phenomenon according to Endler [21], who first distinguished this type of resemblance from "masquerade". In the latter a mimic is perceived by an operator as a discrete entity, which is however misidentified as uninteresting so that the operator also shows no reaction to the mimic. Accordingly, crypsis relies on the relationship between the organism and the background, whereas the benefit of masquerade is thought to be independent of the background [28]. A stick insect, for example, is likely to be recognized as a stick by a potential predator independent of its surroundings (e.g., when lying on grass). A cryptic organism, however, depends strongly on the background. This fact allows testable predictions to be made. For example, a mimic performing masquerade should be treated similarly by the operator independent of its background. On the other hand a mimic that performs crypsis should be treated differently (e.g., recognized and attacked) by the operator when the background changes.

The third column of Table 1 defines adaptive resemblances in which a mimic is perceived by the operator as an entity of interest. This category was first described in a biological context by Bates [29] as "mimicry", and this term is currently most frequently used, hence we adopt it here.

Finally, another mechanism exists to avoid detection by an operator, which is however not based on resemblance. The term "hiding" has been applied to cases in which the absence of informative cues is achieved by behavioral adaptations, making detection by an operator impossible [17]. In visual systems, for example, a rabbit is hiding if it stays in its burrow in the presence of a predator (operator), thereby avoiding detection [17]. If a hiding organism would be removed from the environment, the perceptive input of the operator will not change in the concerning channel. Hiding is not included in Table 1 because it does not fall into categories of resemblance; nevertheless this term will be of importance in our discussion on chemical interactions below.

\section{The Use of Adaptive Resemblance Terms in Chemical Ecology}

Compared to visual adaptive resemblances, chemical adaptive resemblances had initially been paid less attention to in scientific literature, despite the fact that chemical communication is the most widespread form of communication 
among organisms [16, 30, 31]. However, more recent reviews on this topic show that understanding of chemical adaptive resemblance has increased markedly $[11,15,32,33]$.

According to this special issue on ants and their parasites, we focus here particularly on important reviews about parasites of social insects and on reviews about adaptive chemical resemblance. Reviews are suitable for analyzing how the terminology is used, since they provide overviews about specific fields, summarize the literature, and therefore mirror common practices.

We used the same categorization as in Table 1, adopting an operator's point of view. Note that two resemblance types were combined, that is, resemblances in which a mimic is not detected as discrete entity and resemblances in which a mimic is detected as an uninteresting entity (Table 2). We combined these two types of resemblances because none of the reviews distinguished them. Additionally, we included the origins of mimetic compounds in the table, since this is an interesting point regarding chemical resemblances and several authors based their terminology upon it.

Table 2 shows that the terms chemical mimicry and chemical camouflage are not used consistently. Some authors used the terms according to criteria similar to those used in general biology (see Table 1). They distinguished between chemical mimicry as the imitation of an interesting entity and chemical camouflage either as the imitation of an uninteresting entity or as the resemblance of background cues (sensu Dettner and Liepert [15]). This use of terms did not include the origins of mimetic compounds. In contrast, other authors focused primarily on the origin of mimetic cues. According to their terminology, chemical mimicry implies that mimetic cues are biosynthesized by the mimic, while chemical camouflage implies that the mimic acquires mimetic cues from the model (first defined by Howard et al. [38]). Additional definitions specifically focused on a mimic's avoidance of being detected as a discrete entity (Table 2). Chemical resemblances that allow mimics to avoid detection by background matching were defined as chemical mimesis by Akino [14] or as chemical crypsis by Stowe [31].

In addition to adaptive resemblances, another mechanism exists among parasites to prevent detection by an operator. This mechanism was called "chemical insignificance" [39]. However, chemical insignificance was originally brought up to describe the status of freshly hatched ant workers (callows), which typically carry very low quantities of cuticular hydrocarbons [39]. The term insignificance referred to these weak chemical cues, which are frequently not colony or even species specific, allowing the transfer and acceptance of callows into alien colonies [11]. The term chemical insignificance was also adopted to describe a status of ant parasites, which may benefit from displaying no or only small quantities of recognition cues to sneak unnoticed into host colonies $[3,11,39,40]$. We discuss this point in more detail at the end of the following chapter.

Furthermore, chemical transparency was recently described as a chemical strategy in a wasp social parasite [41]. This strategy is somewhat similar to chemical insignificance, except that it refers particularly to a subset of cuticular compounds that are presumably responsible for recognition. We discuss both strategies, chemical insignificance and transparency, in more detail at the end of the following section.

\section{Suggestions for a Consistent Terminology}

As described above, adaptive resemblance terminology is used inconsistently in important reviews of chemical ecology, likely mirroring inconsistent use in this field generally. Most importantly, the terms chemical camouflage and chemical mimicry are inconsistently used by different approaches. While some authors distinguish them according to different models that are mimicked, others distinguish them according to the origin of mimetic cues (Table 2). To avoid confusion, we suggest a consistent terminology that is in line with the definitions used in general biology (Table 1). Consequently, adaptive resemblance of an entity interesting for the operator should be referred to as "chemical mimicry", irrespective of the origin of mimetic cues. Nevertheless, an additional distinction between biosynthesis and acquisition of mimetic cues might often be useful. Hence, we suggest using additional terms to distinguish the origins of mimetic cues; " $a c$ quired chemical mimicry" indicates that mimetic cues are acquired from the model, while "innate chemical mimicry" (as first mentioned by Lenoir et al. [11]) indicates that a mimic has an inherited ability to biosynthesize mimetic compounds. The two different mechanisms may affect coevolutionary dynamics in different ways. For example, a consequence of the acquisition of recognition cues by a parasite from its host is that the mimetic cues of model and mimic are of identical origin [3]. Coevolutionary arms races select in such cases for effective ways of acquiring chemical host cues by the mimic, for example, through specific behaviors such as intensive physical contact to the host. In the host, selection favors counterdefenses which prevent the acquisition of chemical cues. Selection pressures are somewhat different when a parasite biosynthesizes the mimetic cues [3]. In this case, the origins of the chemical cues of mimic and model are different, which allows coevolutionary arms races to shape on the one hand the accuracy of chemical mimicry of the mimic and on the other hand the discrimination abilities of the operator.

Mimics that are not detected as discrete entities or that are detected but misidentified as uninteresting entities by an operator have rarely been addressed in chemical ecological reviews, although they are common in general biology (first two columns of Table 1). Since the term camouflage is not used in general biology to distinguish these two forms of resemblances (Table 1) and since the term chemical camouflage is used inconsistently in chemical ecology (Table 2), we suggest abandoning this term so as to avoid confusion. Instead, we suggest using terms consistent to general biology. Accordingly, "chemical crypsis" describes cases in which an operator is not able to detect a mimic as a discrete entity, while "chemical masquerade" describes cases in which an operator detects a mimic as an uninteresting entity. In both cases, the operator shows no reaction. The terms "acquired" and "innate" can be applied to these categories as well to add further information on the origin of the disguising cues. Note that it is challenging but logically possible to 


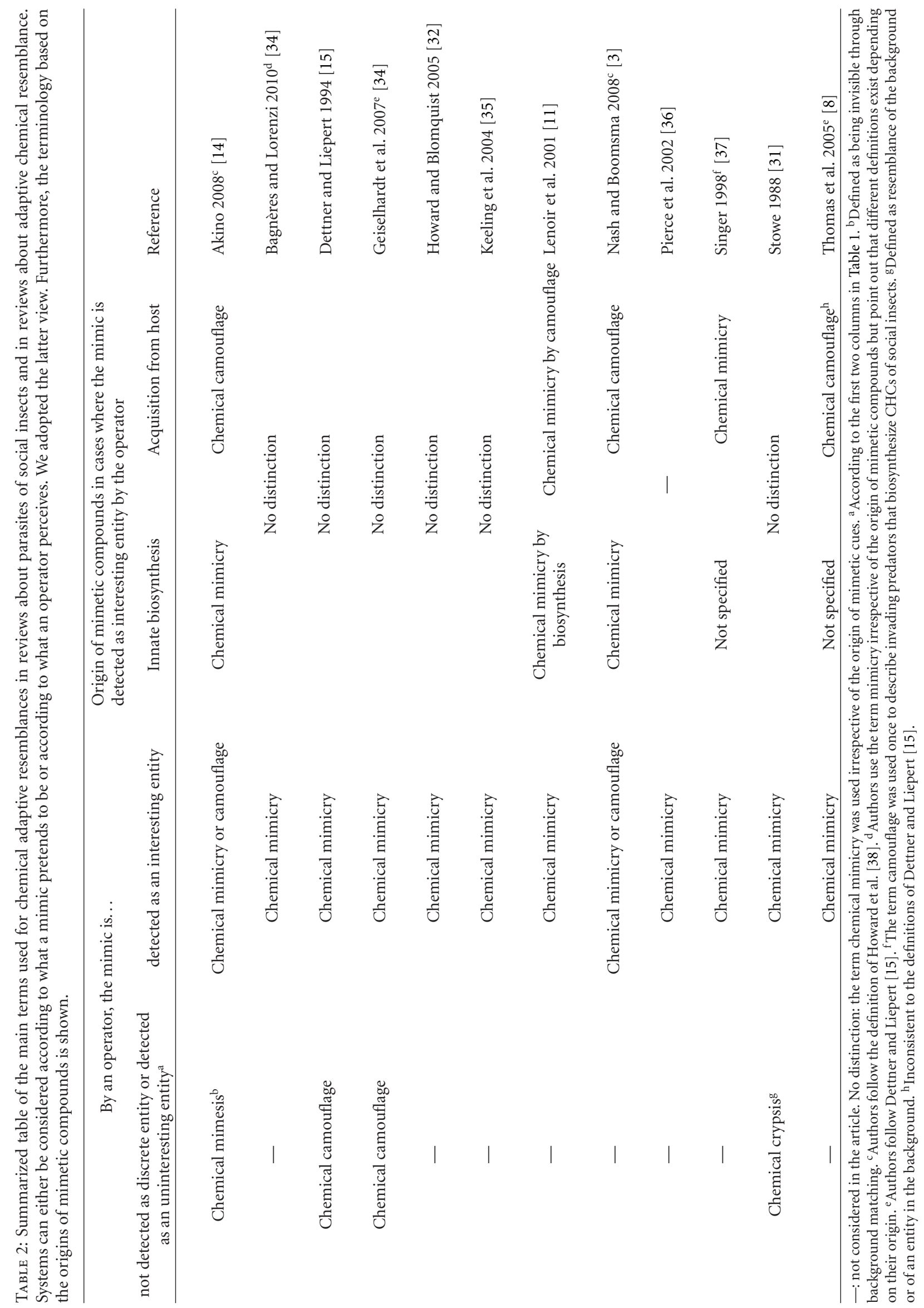


TABLE 3: Proposed terminology for chemical adaptive resemblances. Chemical cues of a mimic can either be "acquired" from the environment (including the host), or they can be "innate", that is, biosynthesized. In all cases of chemical adaptive resemblance, the operator is deceived by the mimic so that the mimic benefits.

\begin{tabular}{|c|c|}
\hline Suggested term & By an operator, the mimic is... \\
\hline Chemical crypsis & $\begin{array}{l}\text {... not detected as a discrete entity due to } \\
\text { the expression of cues that blend with the } \\
\text { environment (causing no reaction in the } \\
\text { operator). }\end{array}$ \\
\hline Chemical masquerade & $\begin{array}{l}\text {... detected but misidentified as an } \\
\text { uninteresting entity (causing no reaction } \\
\text { in the operator). }\end{array}$ \\
\hline Chemical mimicry & $\begin{array}{l}\ldots \text { detected as an entity of interest } \\
\text { (causing a reaction in the operator). }\end{array}$ \\
\hline
\end{tabular}

empirically separate cases of masquerade and crypsis [28], but this has yet to be done in a nonvisual context. Table 3 gives an overview on our proposed terminology for chemical adaptive resemblances. Please note that in our terminology it is only important whether and how mimics are perceived by an operator. Similarities in the chemical profiles of parasites and hosts may be important diagnostic tools, but they are not part of the definitions.

Finally, we want to stress the special case of organisms that suppress the expression of chemical cues which can potentially be detected by the operator. Following our aim of applying a consistent biological terminology, "chemical hiding" is the most appropriate definition. This definition includes two slightly different scenarios, the total absence of relevant cues and the presence of cues below the operator's perceptive threshold. In both cases chemical perception of the organism is impossible. A host's inability to detect any chemical cues of a parasite was also referred to as "chemical insignificance" [3]. However, the term chemical insignificance is unfortunately used ambiguously regarding the important point whether there are no detectable cues [3] or small yet detectable amounts of cues are present [39]. Clearly, it should be distinguished whether an operator is able to detect an organism or not. If resemblance cues are present and perceived (irrespective of the quantitative level), the phenomenon will fall per definition into one of the categories chemical crypsis, chemical masquerade, or chemical mimicry (Table 3). For example, if a callows' weak chemical signature was expressed by a parasite and adult host ants misidentified this parasite as a callow, we would follow Ruxton [17] by assigning this to chemical mimicry (since callows are certainly interesting entities). Empirical evidence for a chemical mimicry of callows could result in practice from a combination of chemical data (callow resemblance) and behavioral data (hosts treat parasite as callows). However, an exhaustive discussion about methods is beyond the scope of this conceptual paper. Consequently, the original definition of chemical insignificance as a "weak signal" [39] appears not applicable to parasites without the risk of confusing it with chemical mimicry. If chemical cues are below an operator's perceptive threshold, the definition of chemical hiding will apply. However, the term chemical insignificance may be used as a functional term describing the lack of chemical information in a certain context. For example, callows are chemically insignificant in terms of nestmate recognition due to a lack of chemical information in that context. Nevertheless, callows carry apparently sufficient information in the context of caste identity since workers show characteristic behaviors towards them; for example, they receive assistance during hatching and are transported to new nest sites in migratory ants.

The above discussion on chemical insignificance applies also to the phenomenon of chemical transparency. If no cues are expressed that are perceivable by the operator, the focal organism would show chemical hiding, regardless of the presence of any other compounds. In contrast, if perceivable cues are present, chemical crypsis, chemical masquerade, or chemical mimicry applies. In the described case of chemical transparency [41], the parasite is most likely recognized and misidentified as an interesting entity (e.g., as brood), since social parasites usually exploit the brood care behavior of their hosts.

Notably, a parasite may alternatively avoid chemical detection through behavioral mechanisms by "hiding" according to the definition in general biology (see above) rather than "chemical hiding." For example, if it avoids detection by staying in a cavity so that its chemical cues do not reach the operator, it is hiding. A parasite that performs "hiding" could potentially be detected if it was somehow confronted with the operator. In contrast, a parasite that shows "chemical hiding" cannot be detected by chemical senses of the operator at all.

\section{Examples for the Use of Adaptive Resemblance Terms}

In this section we want to discuss examples to clarify the use of terms regarding adaptive resemblances. The mimicking of $\mathrm{CHC}$ profiles of the host is widespread among ant parasites, and this is generally assumed to facilitate integration into the host colonies. Parasites are indeed frequently not recognized as alien species $[11,33]$. This strategy of avoiding recognition as an alien species by expression of host CHCs could potentially be referred to as chemical crypsis (if the colony odor is regarded as the background) or as chemical masquerade (if a nestmate worker is regarded as an uninteresting entity). However, we argue that the strategy is best described by chemical mimicry for the following reasons. First, workers are certainly able to detect other workers, and hence parasites that mimic them are discrete entities, excluding the term chemical crypsis. Second, workers are certainly interesting entities to other workers because social actions are shared, such as grooming or trophallaxis. Consequently, a mimic that uses a worker as model resembles an entity of potential interest to ant workers, so that chemical mimicry rather than chemical masquerade applies.

It becomes more complicated when a parasite mimics the nest odor of its host. Lenoir et al. [42] demonstrated that the inner nest walls of the ant species Lasius niger are coated with the same CHCs as those that occur on the cuticle of workers. However, the CHCs on the walls occurred in different 
proportions and showed no colony specificity. If a mimic resembles such a chemical profile, chemical crypsis will be the most appropriate term, because the mimic represents no discrete entity and rather blends with the uniform nest odor. To our knowledge, no clear evidence exists for this case.

Another example is worth highlighting in this context which was already pointed out by Ruxton [17]. The CHCs of Biston robustum caterpillars resemble the surface chemicals of twigs fr om its host plant [43]. Formica japonica and Lasius japonicus workers do not recognize the caterpillars on their native host plant, but when caterpillars were transferred to a different plant, the ants noticed and attacked them. In this case it depends on the operator's perception whether the example should be considered as chemical crypsis or chemical masquerade. If the ants did not detect a twig (and hence a caterpillar) as a discrete entity, but as background, chemical crypsis would apply. If the ants detected the caterpillar as a discrete but uninteresting entity, for example, as a twig, then chemical masquerade would apply. As Ruxton [17] emphasized, twigs are of huge dimension compared to the size of ants. Hence, it is more likely that ants do not detect caterpillars as discrete (uninteresting) entities, but rather perceive them as (uninteresting) background. Accordingly, chemical crypsis appears to be the most appropriate term for this example.

These examples may demonstrate that it can be rather difficult to assign appropriate terms to particular adaptive resemblance systems. Nevertheless, the definitions we proposed are generally straightforward, and they can be applied unambiguously if the necessary information about a system is available. We hope that this paper contributes to a careful and consistent use of adaptive resemblance terminology in chemical ecology.

\section{Acknowledgments}

The authors thank the behavioral ecology group at the LMU Munich and Graeme D. Ruxton for valuable comments. They are grateful to the editor Alain Lenoir and two anonymous reviewers for their effort to improve this paper. Thanks to Tomer Czaczkes for checking the orthography. The authors are grateful for financial support from the DFG (Deutsche Forschungsgemeinschaft, Project WI 2646/3).

\section{References}

[1] E. O. Wilson, "Success and dominance in ecosystems: the case of the social insects," in Excellence in Ecology, Ecology Institute, Oldendorf/Luhe, Germany, 1990.

[2] P. S. Ward, "Ants," Current Biology, vol. 16, no. 5, pp. R152R155, 2006.

[3] A. Nash and J. J. Boomsma, "Communiction between hosts and social parasites," in Sociobiology of Communication an Interdisciplinary Approach, P. d'Ettorre and D. P. Hughes, Eds., Oxford University Press, New York, NY, USA, 2008.

[4] P. Schmid-Hempel, Parasites in Social Insects, Princeton University Press, Princeton, NJ, USA, 1998.

[5] B. Hölldobler and E. O. Wilson, The Ants, Harvard University Press, Cambridge, Mass, USA, 1990.
[6] J. J. Boomsma, P. Schmid-Hempel, and W. O. H. Hughes, "Life histories and parasite pressure across the major groups of social insects," in Insect Evolutionary Ecology: Proceedings of the Royal Entomological Society, M. D. E. Fellowes, G. J. Holloway, and J. Rolff, Eds., pp. 139-176, CABI Publishing, Wallingford, Conn, USA, 2005.

[7] E. Wasmann, "Die Ameisen-und Termitengäste von Brasilien. I. Teil. Mit einem Anhange von Dr. August Forel.," Verhandllungen der kaiserlich-königlichen zoologisch-botanischen Gesellschaft in Wien, vol. 45, pp. 137-178, 1895.

[8] J. A. Thomas, K. Schönrogge, and G. W. Elmes, "Specializations and host associations of social parasites of ants," in Insect Evolutionary Ecology Proceedings of the Royal Entomological Society, M. D. E. Fellowes, G. J. Holloway, and J. Rolff, Eds., CABI Publishing, Sheffield, UK, 2005.

[9] R. Dawkins and J. R. Krebs, "Arms races between and within species," Proceedings of the Royal Society of London B, vol. 205, no. 1161, pp. 489-511, 1979.

[10] J. S. van Zweden and P. d'Ettorre, "Nestmate recognition in social insects and the role of hydrocarbons," in Insect Hydrocarbons Biology, Biochemistry and Chemical Ecology, G. J. Blomquist and A.-G. Bagnères, Eds., Cambridge University Press, New York, NY, USA, 2010.

[11] A. Lenoir, P. D’Ettorre, and C. Errard, "Chemical ecology and social parasitism in ants," Annual Review of Entomology, vol. 46, pp. 573-599, 2001.

[12] K. Dinter, W. Paarmann, K. Peschke, and E. Arndt, "Ecological, behavioural and chemical adaptations to ant predation in species of Thermophilum and Graphipterus (Coleoptera: Carabidae) in the Sahara desert," Journal of Arid Environments, vol. 50, no. 2, pp. 267-286, 2002.

[13] F. Barbero, J. A. Thomas, S. Bonelli, E. Balletto, and K. Schönrogge, "Queen ants make distinctive sounds that are mimicked by a butterfly social parasite," Science, vol. 323, no. 5915, pp. 782-785, 2009.

[14] T. Akino, "Chemical strategies to deal with ants: a review of mimicry, camouflage, propaganda, and phytomimesis by ants (Hymenoptera:Formicidae) and other arthropods," Myrmecological News, vol. 11, pp. 173-181, 2008.

[15] K. Dettner and C. Liepert, "Chemical mimicry and camouflage," Annual Review of Entomology, vol. 39, pp. 129-154, 1994.

[16] S. Steiger, T. Schmitt, and H. M. Schaefer, "The origin and dynamic evolution of chemical information transfer," Proceedings of the Royal Society B, vol. 278, no. 1708, pp. 970-979, 2011.

[17] G. D. Ruxton, "Non-visual crypsis: a review of the empirical evidence for camouflage to senses other than vision," Philosophical Transactions of the Royal Society B, vol. 364, no. 1516, pp. 549-557, 2009.

[18] A. Starrett, "Adaptive resemblance: a unifying concept for mimicry and crypsis," Biological Journal of the Linnean Society, vol. 48, no. 4, pp. 299-317, 1993.

[19] W. Wickler, Mimikry. Nachahmung und Täuschung in der Natur, Kindlers Universitäts Bibliothek, München, Germany, 1968.

[20] R. I. Vane-Wright, “On the definition of mimicry," Biological Journal of the Linnean Society, vol. 13, no. 1, pp. 1-6, 1980.

[21] J. A. Endler, "An overview of the relationships between mimicry and crypsis," Biological Journal of the Linnean Society, vol. 16, no. 1, pp. 25-31, 1981.

[22] J. A. Endler, "Frequency-dependent predation, crypsis and aposematic coloration," Philosophical Transactions of the Royal Society of London B, vol. 319, no. 1196, pp. 505-523, 1988. 
[23] G. Pasteur, "A classificatory review of mimicry systems," Annual Review of Ecology and Systematics, vol. 13, pp. 169-199, 1982.

[24] M. H. Robinson, "A stick is a stick and not worth eating: on the definition of mimicry," Biological Journal of the Linnean Society, vol. 16, no. 1, pp. 15-20, 1981.

[25] G. D. Ruxton, T. N. Sherratt, and M. P. Speed, Avoiding Attack: The Evolutionary Ecology of Crypsis, Warning Signals and Mimicry, Oxford University Press, New York, NY, USA, 2004.

[26] M. Stevens and S. Merilaita, "Animal camouflage: Current issues and new perspectives," Philosophical Transactions of the Royal Society B, vol. 364, no. 1516, pp. 423-427, 2009.

[27] R. I. Vane-Wright, "A unified classification of mimetic resemblances," Biological Journal of the Linnean Society, vol. 8, no. 1, pp. 25-56, 1976.

[28] J. Skelhorn, H. M. Rowland, and G. D. Ruxton, “The evolution and ecology of masquerade: review article," Biological Journal of the Linnean Society, vol. 99, no. 1, pp. 1-8, 2010.

[29] H. W. Bates, "Contributions to an insect fauna of the Amazon valley (Lepidoptera: Heliconidae)," Transactions of the Linnean Society of London, vol. 23, no. 3, pp. 495-566, 1862.

[30] M. R. E. Symonds and M. A. Elgar, "The evolution of pheromone diversity," Trends in Ecology and Evolution, vol. 23, no. 4, pp. 220-228, 2008.

[31] M. K. Stowe, "Chemical mimicry," in The Chemical Mediation of Coevolution, K. C. Spencer, Ed., Academic Press, New York, NY, USA, 1988.

[32] R. W. Howard and G. J. Blomquist, "Ecological, behavioral, and biochemical aspects of insect hydrocarbons," Annual Review of Entomology, vol. 50, pp. 371-393, 2005.

[33] A.-G. Bagnères and M. Lorenzi, "Chemical deception/mimicry using cuticular hydrocarbons," in Insect hydrocarbons Biology, Biochemistry and Chemical Ecology, G. J. Blomquist and A.-G. Bagnères, Eds., Cambridge University Press, New York, NY, USA, 2010.

[34] S. F. Geiselhardt, K. Peschke, and P. Nagel, "A review of myrmecophily in ant nest beetles (Coleoptera: Carabidae: Paussinae): linking early observations with recent findings," Naturwissenschaften, vol. 94, no. 11, pp. 871-894, 2007.

[35] C. I. Keeling, E. Plettner, and K. N. Slessor, "Hymenopteran semiochemicals," Topics in Current Chemistry, vol. 239, pp. 133-177, 2004.

[36] N. E. Pierce, M. F. Braby, A. Heath et al., "The ecology and evolution of ant association in the Lycaenidae (Lepidoptera)," Annual Review of Entomology, vol. 47, pp. 733-771, 2002.

[37] T. L. Singer, "Roles of hydrocarbons in the recognition systems of insects," American Zoologist, vol. 38, no. 2, pp. 394-405, 1998.

[38] R. W. Howard, R. D. Akre, and W. B. Garnett, "Chemical mimicry in an obligate predator of carpenter ants (Hymenoptera: Formicidae)," Annals of the Entomological Society of America, vol. 83, pp. 607-616, 1990.

[39] A. Lenoir, D. Fresneau, C. Errard, and A. Hefetz, "Individuality and colonial identity in ants: the emergence of the social representation concept," in Information Processing in Social Insects, C. Detrain, J. L. Deneubourg, and J. Pasteels, Eds., Birkhäuser, Basel, Switzerland, 1999.

[40] R. M. Kilner and N. E. Langmore, "Cuckoos versus hosts in insects and birds: adaptations, counter-adaptations and outcomes," Biological Reviews, vol. 86, no. 4, pp. 836-852, 2011.

[41] S. J. Martin, J. I. Takahashi, M. Ono, and F. P. Drijfhout, "Is the social parasite Vespa dybowskii using chemical transparency to get her eggs accepted?" Journal of Insect Physiology, vol. 54, no. 4, pp. 700-707, 2008.
[42] A. Lenoir, S. Depickère, S. Devers, J. P. Christidès, and C. Detrain, "Hydrocarbons in the ant Lasius niger: from the cuticle to the nest and home range marking.," Journal of Chemical Ecology, vol. 35, no. 8, pp. 913-921, 2009.

[43] T. Akino, K. I. Nakamura, and S. Wakamura, "Diet-induced chemical phytomimesis by twig-like caterpillars of Biston robustum Butler (Lepidoptera: Geometridae)," Chemoecology, vol. 14, no. 3-4, pp. 165-174, 2004. 

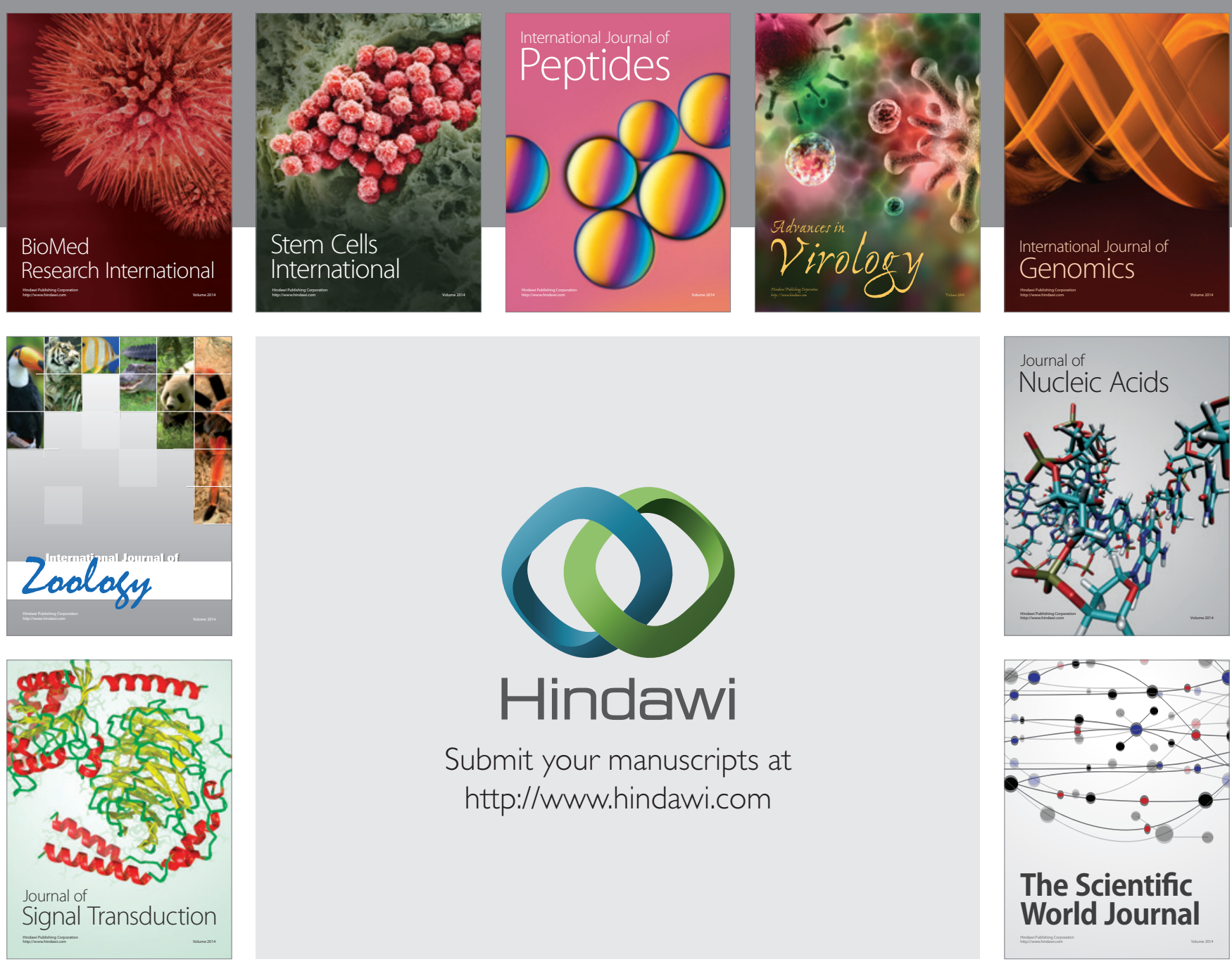

Submit your manuscripts at

http://www.hindawi.com
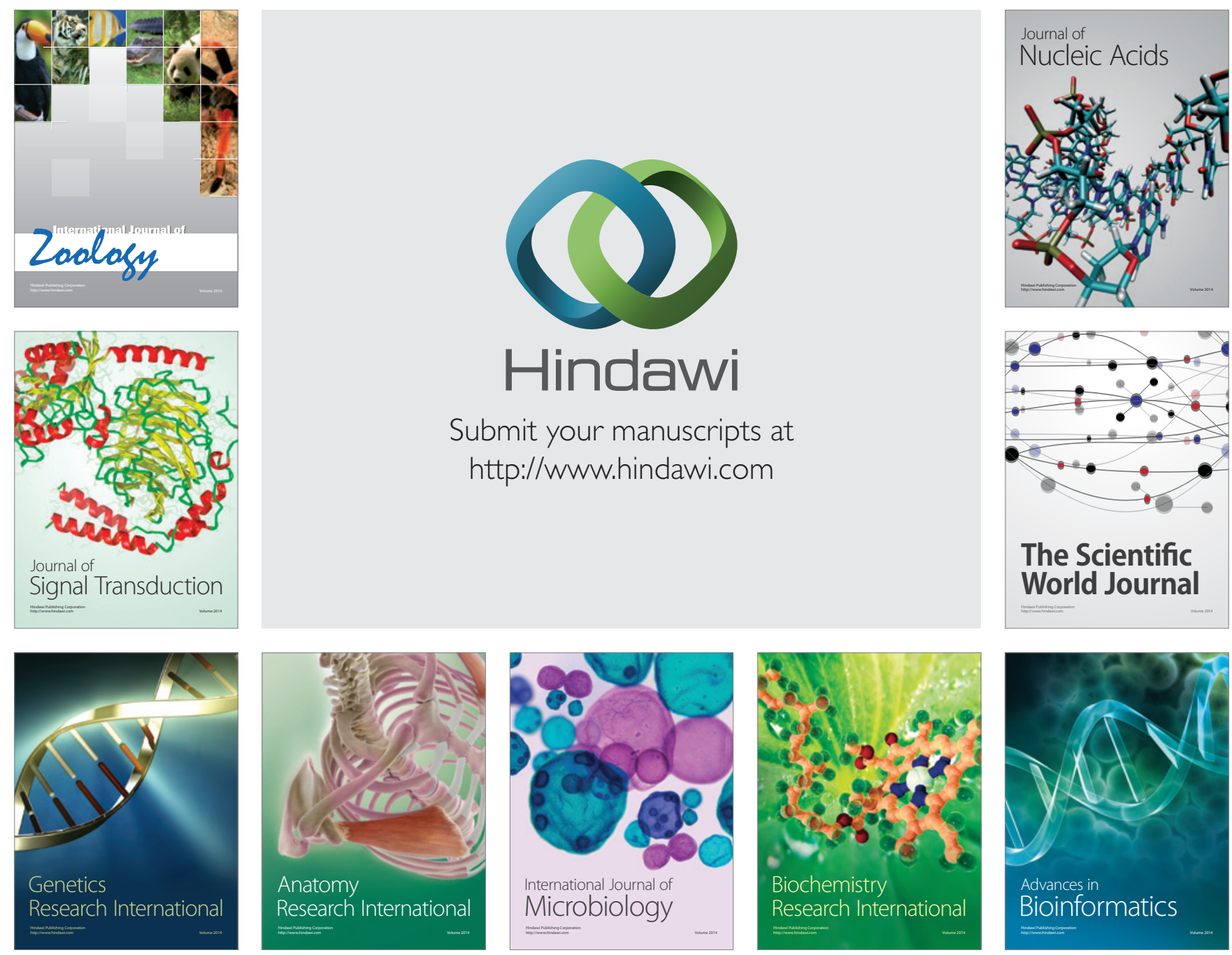

The Scientific World Journal
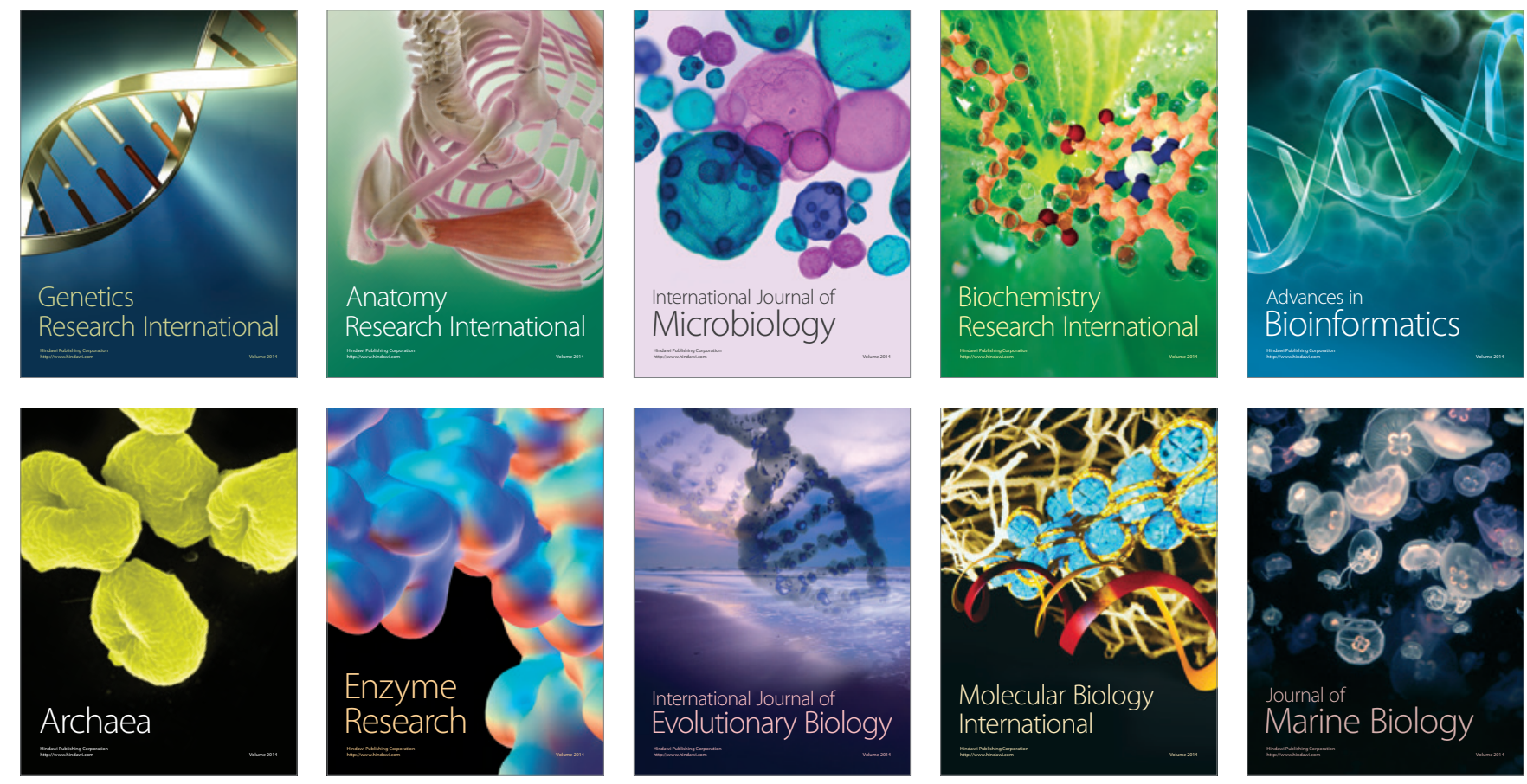